\title{
Institutionalising knowledge brokering as a sustainable knowledge translation solution in healthcare: how can it work in practice?
}

S. E. Chew, N. Armstrong and G. P. Martin

\begin{abstract}
In healthcare, translating evidence into changed practice remains challenging. Novel interventions are being used to address these challenges, including the use of 'knowledge brokers'. But how sustainable these roles might be, and the consequences for the individual of enacting such roles, are unknown. We explore these questions by drawing on qualitative data from case studies of full-time roles in research-practice collaboration. We suggest that structural issues around professional boundaries, organisational norms and career pathways may make such roles difficult to sustain in the long-term, but highlight interventions that might improve their feasibility.
\end{abstract}

Key Words: Knowledge translation, Knowledge brokers, Intermediaries, Healthcare, Qualitative Acknowledgements: The research was funded by the National Institute for Health Research (NIHR) Collaboration for Leadership in Applied Health Research and Care. The views expressed are those of the authors and not necessarily those of the NHS, the NIHR or the Department of Health. 


\section{Introduction}

It has been documented in many fields that persistent gaps exist between what research shows to be effective and what actually happens in policy and practice. In healthcare, the adoption of validated innovations is less than 50\% (Haynes and Haynes, 2009). This 'knowledge-translation deficit' results in wasted resources and avoidable health inequalities (Lyons, 2010:11). Thus, the challenge of getting evidence into practice is a pressing political and social concern (Kerner, 2006; Estabrooks et al., 2008). However, the process of translating research knowledge into practice is recognised to be idiosyncratic and complex, demanding the engagement of multiple actors and changes in systems and practice (Fixsen et al., 2005; Mitton et al, 2007).

Clearly, addressing this situation means identifying impediments to knowledge translation and developing ways to overcome them. Areas in which impediments might exist have been identified (for a summary, see Haines et al, 2004, Oborn et al, 2010). In the UK, the research process itself is under scrutiny. Recent government documents (e.g. Cooksey, 2006; Tooke, 2007) acknowledge that it is no longer valid to assume a unidirectional model of knowledge transfer in which research findings automatically lead to change in policy and practice (Britten, 2010). Concomitantly, there has been a shift among policy makers towards new translational models in which the future users of evidence are acknowledged as key actors in the process of its production (Oborn et al., 2010). 
In the English healthcare system, perhaps the most prominent example of initiatives that seek to act upon this new thinking about the knowledge-translation process is the National Institute for Health Research's programme of Collaborations for Leadership in Applied Health Research and Care (CLAHRCs). CLAHRCs are intended to develop mutually beneficial partnerships between research institutions and NHS organisations. They aim to improve patient outcomes by increasing stakeholder participation in research and adapting research to fit the needs of practice. Amongst other strategies, several CLAHRCs have introduced 'knowledge brokers'; intermediary roles between research and practice which are thought to have considerable translation potential.

Using intermediary roles as part of the solution to the translational deficit makes intuitive sense, in light of the novel models of research translation alluded to above. These models attend to the relationship of tacit knowledge- 'knowing in practice' - to the dissemination of explicit codified knowledge-'knowing in theory' (Davies et al., 2011).Thus, they emphasise the importance of interaction between the practice and research communities. Initiatives informed by such models often use interventions aimed at enhancing and facilitating this interaction-such as intermediary knowledge-brokering roles. However, the enthusiasm shown towards knowledge brokering as a solution to the translational problem belies a lack of evidence supporting its efficacy. Evidence from literatures beyond those usually cited in support of knowledge-brokering roles in healthcare suggests that institutionalising and enacting such work in practice may not be straightforward, not least due to the 
unusual, 'outlying' nature of such roles. These problems have been little explored in the context of healthcare organisations.

This paper, therefore, seeks to explore intermediary roles from the role-holders' standpoint, examine the impact of enacting such roles on the individual, and the potential impact of these individual-level consequences for the longer-term viability of intermediary roles as a knowledge-translation solution. In the next section we discuss the existing literature in more detail. We then introduce the empirical field in which this study was undertaken and describe our methods, before presenting our findings and discussing the implications of these for efforts to institutionalise and embed such roles as a key component in the knowledge-translation armoury. Evidence from literatures previously untapped in healthcare, combined with our empirical insights, calls into question the sustainability of such roles, at least in the form of dedicated, full-time positions that occupy a liminal space between research and practice.

\section{Intermediary work and 'knowledge brokering'}

Three broad functions of intermediary roles have been identified in contemporary healthcare research: 'knowledge management', 'linkage and exchange', and 'capacity building' (Ward et al., 2009; Oldham, 1997). These align with ideas from other fields where intermediary roles are used (Stovel and Shaw, 2012; Williams, 2002). Knowledge management involves making existing evidence more accessible, for example, by reproducing it in summary form or in language appropriate to users. It can also encompass consultation with users in order to commission research that aligns with their needs. The principle behind this approach is relevance: if evidence is 
commissioned, tailored or produced in a form relevant to users, it is more likely to be taken up (Ward et al., 2009). 'Linkage and exchange' refers to facilitating collaborative problem-solving (CHSRF, 2003). Bringing about interaction between stakeholders results in 'mutual learning through the process of planning, producing, disseminating, and applying existing or new research in decision-making' (CHSRF,2003). Finally, 'capacity building' involves enhancing the skills of those involved in the research process, such as communication, analytical and evaluative skills (Newlands, 1981). The intention is that participants become self-reliant, so local sustainable capacity to use or generate research evidence is created. Intermediary work tends to involve a strategic blend of these functions, tailored to specific contexts (Meyer, 2010; Jackson Bowers et al, 2008).

Even before the current interest in intermediary knowledge-translation roles, work undertaken to help goods, information or knowledge flow across gaps between social groups (Stovel and Shaw, 2012), attracted interest in diverse research domains (see for example, Simmel, 1950; Tushman, 1977). However, much relevant evidence from similar projects in other fields remains underutilised in the context of translational health research initiatives, where the concept of 'knowledge brokerage' is often considered novel (e.g. Gerrish, 2011). Across these literatures different terms are used synonymously, with 'boundary spanning' and 'knowledge brokering' the most common (Williams, 2002; Zaim et al., 2009). Henceforward, we use the term 'intermediary', as this is the common defining feature of numerous overlapping terms. In this way, we seek to avoid privileging the phrasing used in one field over another, 
foregrounding instead the crucial commonality between these bodies of literature: that boundaries must necessarily be spanned in order to broker knowledge.

As above, the functional purpose of such roles, and the means by which they might, in theory, engender change, are well documented, but there is less certainty about their effectiveness in practice. Recent quantitative research in healthcare has shown mixed results for short-term, knowledge management-based intermediary interventions (Dobbins et al., 2009;Russell, 2010). It seems unlikely that a consistent evidence base on the effectiveness of intermediary interventions will emerge, given the breadth of the concept, its context-dependent and contingent nature, and the complexity of the social processes involved —all of which will confound experimental research approaches. The problems with evaluating the effectiveness of such interventions point towards an underlying problem in practice: that many of the effects of intermediary roles are difficult to delimit and attribute as the direct outcomes of intermediary work, due to its typically temporally distributed and unpredictable nature. This then raises questions about how, at the practice level, such roles and the performances of those in them can be managed and appraised, and what this might mean for those involved.

In summary, there has been increased use of intermediaries to facilitate knowledge translation in healthcare contexts, but the effectiveness of this is uncertain and may remain indeterminable. Rather less consideration, however, has been given to the impact on, and the consequences for, individuals working in dedicated intermediary roles. Furthermore, as we discuss next, evidence from beyond the 
healthcare-specific literature suggests that problems associated with intermediary work exist and seem to be especially acute in full-time posts of the kind that are increasingly posited as a solution to the knowledge-translation problem. These individual-level problems may have implications for the potential utility and sustainability of the roles themselves.

\section{Individual-level consequences and the full-time intermediary}

Some research beyond healthcare has centred on the experience of the intermediary actor. This identifies and indicates problems which derive from the ways intermediary roles differ from other organisational roles. For example, Knight and Lightowler's (2010) work in universities highlights recruitment, management and accountability, recognition and integration, professional support, and development, reward, promotion and career pathways as problematic areas. For example, if one's work is mainly concerned with linkage and exchange or capacity-building activities, how can success adequately be captured and quantified? How might recognition be gained for one's work, given that it may be temporally and spatially distributed? A further consideration is the uncertainty of effectiveness; the intermediary often cannot know which of the activities they undertake will ultimately be successful, or attribute causation retrospectively. Therefore they cannot be sure where to direct their effort or whether their effort will be worthwhile (Needleman \& Needleman, 1974). The repercussions of this are likely to be particularly significant for full-time intermediaries, whose roles may be largely dedicated to activities, the effectiveness of which is unascertainable. 
Relationships with the groups engaged by intermediaries may also be problematic. Intermediaries have been theorised as enacting their roles in a unique space, engaged with and equidistant from, the parties with whom they work (Stovel \& Shaw, 2012; Lomas, 2007). However, empirical evidence outside healthcare has shown their position can be unstable, and maintaining equilibrium may not be achievable in practice.

Further, evidence suggests that actors undertaking intermediary roles may experience them as stressful. Intermediary activities have been found to be strongly associated with two forms of employee stress: role conflict and role ambiguity (Stamper \& Johlke, 2003). The first of these occurs when third parties' expectations of a role conflict and the individual must manage competing demands. Intermediary work involves social interaction with diverse audiences, demanding the management of variable and often complex requirements (Stamper \& Johlke, 2003).

Role ambiguity develops when norms for a specific position are vague, unclear and ill-defined, as might be expected in intermediary undertakings which, as above, involve a recurrent process of evaluation and tailoring. The consequences of such stress are unclear. On one hand, it is documented that stress generally interferes with novel or creative responses, inhibits motivation, and negatively affects both performance and self-esteem (Farr \& Ford, 1990). That said, others assert that role stress can prove positive, in that exposing individuals to different perspectives may make them more flexible, creative and open to new information (Tang \& Chang, 2010). Social support, whether from the organisation or co-workers, has been 
suggested to account for the difference, by moderating the effects of stress (Stamper and Johlke, 2003).

In summary, in the context of healthcare research, intermediary roles are seen as novel interventions which have the potential to be an effective part of efforts to improve knowledge translation. Formalised, full-time intermediary roles have been established as part of translational initiatives in healthcare. However, evidence for the effectiveness of these roles is lacking, and there is evidence from other contexts that putting them into practice can be challenging for the role-holder. The breadth of such roles, and the complex social environments in which they are enacted, make for an environment in which role ambiguity and role conflict can result. These may impact negatively on the role-holder, though it is not clear from the existing evidence base how far this impacts on the potential of these roles, as translational aids, to be fully realised. This does, however, raise questions about the sustainability and, consequently, the potential of such interventions.

This paper, therefore, seeks to address these questions, by exploring the enactment of full-time intermediary roles, its impact on role-holders in terms of their personal experience of such work, and the consequences for the viability of intermediary roles in bridging the knowledge-translation gap. We draw on a longitudinal analysis of seven cases of formalised intermediary roles enacted in different healthcare organisations: partners in a translational initiative involving research and practice organisations ('County CLAHRC'). We find many of the challenges suggested by the wider literature, beyond healthcare, to have salience in 
this context, but we also highlight the way in which, over time, these were mediated through the individual and collective agency of the role-holders. We then discuss implications for policy and practice in the design and management of these roles, suggesting how they might be better supported so that deleterious individual-level consequences might be minimised — and the potential contribution of such roles might be maximised.

Our study is based in one of nine CLAHRCs across England funded from 2008, consisting of one university and several NHS organisations. The intermediaries in County CLAHRC are NHS employees hosted by NHS organisations, and are linemanaged, day-to-day, by NHS managers, though their activities are jointly directed by the core partnership. A County CLAHRC document states that the overarching remit of the posts is to 'promote evidence use within the host organisations, recruit personnel to participate in new forms of locally driven knowledge production, facilitate evidence use by tailoring and synthesis, and establish and maintain interorganisational and interpersonal linkage'.

\section{Methods}

Since this field had not been previously researched, we took a grounded theory-based approach to our study. The work presented here derives from one emergent research category, 'living the life of an intermediary', within an on-going longitudinal study. Early on in the data collection, described below, we became sensitised to issues of how enacting the roles impacted on the actors. These were then pursued using an 
interactive and inductive approach. Throughout the process we used constant comparison to develop our analysis, collect the data and explore the literature (Glaser, 1965). Over six months, candidate themes/theories were developed; these were repeatedly tested for theoretical consistency and validity in regular meetings between the authors and in consultation with the participants.

Data collection included individual interviews (lasting on average an hour), a three-hour focus group with all intermediaries, and 118 hours of workplace ethnographic observation (these observations informed other aspects of the work, but we do not draw on them directly in this paper). Furthermore, a wide range of organisational documents were collected, including job descriptions and meeting minutes. Additionally, we drew on Zimmerman and Wiedener's (1977) 'diary interview' method, in which diaries serve as a means of eliciting concepts for subsequent research interviews as well as acting as a data source in themselves. The diaries were solicited in July 2010, all post-holders agreed to participate, and instalments of the diaries were fed back to the researchers on an ad-hoc basis. These were then used to inform semi-structured interviews in early 2011. Initially, S.E.Chew read the diaries closely, and identified and ordered entries incorporating statements relating to affect and lived experience, leading to the collation of recurrent themes. These themes formed sensitising concepts to inform the subsequent interviews. The interviews comprised general questions and questions specifically relevant to each participant. An advantage of this method was that questions around issues that were important to one individual could be explored with others who may not have explicitly identified them. The interviews also formed an additional process by which the 
researchers' interpretations of the diary data could be explored and validated with the participants.

\section{Findings}

Our findings are structured longitudinally, beginning with a brief account of the creation of the roles and of the key activities they involved. Then, in 'Being an intermediary', we recount a collective narrative of a common experiential pathway initially characterised by uncertainty and isolation. Over several months, we see a change; the conditions of the roles come to be framed positively, and are latterly considered to provide autonomy and opportunity. The next section, 'Making sense and moving forward' centres on this change and the reasons for it. However, challenges remain and these are discussed in the final section, Unresolved and irresolvable?' Pseudonyms are used for all data extracts.

\section{Background: realising the roles}

There's about a million and one things that you might want to do and by the end of it can you change the culture of the NHS in three years please...[Jan, Interview]

The creation of the roles was a lengthy, complex process, with 'banding' a key problem. In NHS organisations, new posts are banded in line with other similar posts; the novelty of the intermediary posts proved problematic and heralded lengthy negotiations between the collaboration's partners. Consequentially, the posts were 
filled at different times, up to 18 months into the partnership. County CLAHRC policy stated that the role was to "provide the crucial link between NHS trusts and academia to ensure CLAHRC is working collaboratively to deliver its aims and objectives'. The job descriptions included activities and responsibilities that could encompass all the components of intermediary work described above. This breadth was reflected in the eventual range of activities that the intermediaries became involved in. For example, capacity development work was undertaken to better enable trust staff to routinely use evidence. This included identifying local needs, developing training sessions that would address these, organising their delivery in ways that were tailored to local demands and conducting on-going evaluations of these. Knowledge management work included translating clinical and management questions into research questions, summarising evidence, and other forms of project support. Much linkage and exchange work was also undertaken, with activities ranging from encouraging and supporting joint working within the collaboration to building links to other external NIHR networks (for example, the MHRN [Mental Health Research Network] and the PCRN [Primary Care Research Network]). The activities differed markedly at times from one trust to another and therefore the intermediary roles differed accordingly. For example, interest in research training in the trusts varied widely. In trusts where there was little, the intermediary work centred on why this might have been the case and what could be done to remedy this, thus illustrating the 'responsive' aspect of such work. 


\section{'Being an intermediary'}

Feeling very lonely this week and a little lost, I had forgotten how [important] just having a team to have a chat [with] and run ideas past was. [Sam, Diary]

Many data from the intermediaries' early time in the posts included expressions of loneliness and isolation. Reasons cited included a lack of opportunity to interact with colleagues who either shared a similar remit or who understood the purpose of the intermediary roles. For some, the geographical location of the posts compounded this social isolation, in that the intermediary was physically distanced from their potential client base. This limited the opportunity for informal, 'water cooler' encounters with other trust personnel.

Developing a role identity within the local organisation also proved problematic:

I sit in an office with a secretary and IT, I'm on my own and I don't fit within any structure and so I basically just have to make my way from there out into the big wide world. [Ali, Diary]

When we first started I think there was a lot of work around trying to figure [out] what we were actually selling and whether we had anything to sell. [Jan, Interview]

As a result, role ambiguity was widespread. The novelty of the roles created an impediment to establishing a role identity; both for others within the organisations in 
relation to the intermediaries and for the intermediaries to develop an identity for themselves in relation to others in the organisation. In contrast to usual roles in organisations, neither party had a pre-existing frame of reference to draw upon. It was, therefore, unclear what the norms and expectations associated with the roles might be. As the second quotation above reveals, it was recognised that remedying this was part of the intermediaries' remit, in that they had a responsibility for promoting themselves and the partnership within the trusts. However, uncertainty surrounding a strategy for action, the range of possible actions available, and the scale of the potential client base proved daunting.

The absence of pre-given norms was further consequential in that the intermediaries tended to evaluate the roles in terms of their expectations of usual organisational roles and previous work experience:

There is little formal support provided for intermediaries in terms of introducing a new intermediary to: colleagues within [County CLAHRC], existing work streams, standardised templates/processes for initiating contacts and progressing work. [Pat, Diary]

You've got no idea what you're supposed to be doing; well I didn't. [Chris, Interview]

In light of these expectations, the uncertainty experienced was not easily recognised as an inherent feature of the roles. In the second quotation above, Chris adds the qualification "well I didn't" after the expression of uncertainty. This qualification typifies others found in the early data and illustrates a belief that the uncertainty they 
were experiencing might be indicative of a personal shortcoming rather than a more general issue. Worries also concerned expectations about how their performance in the posts would be evaluated. Several intermediaries stated that they assumed there to be a formal set of criteria by which their performance would be judged, and according to which they might be found wanting:

When I first started I spent the first couple of weeks or months really, really panicking that somebody was going to come to me and say 'why haven't you done this, you haven't done this, you haven't done this' and it was because I didn't know what I was doing but I was really, really concerned. [Jo, Interview]

The management of the roles was also beset with uncertainty. While they were line-managed locally, in accordance with the principles of collaboration, the posts' activities were jointly directed by the partners in the collaboration, and so in addition to a manager each intermediary also had a 'supervisor' based in the university. Approaches to management varied: some NHS managers were directive; others took a more remote stance. Some had limited contact with the core partnership and were uncertain about how best to manage the roles and what support or direction could or should be given. Whilst an external sense of direction was, at this time, considered desirable by intermediaries, one that was locally generated by their host organisation unilaterally could be problematic. Being directive depended on a manager independently forming a strategy for realising County CLAHRC's aims based on her/his own interpretation of these aims. The CLAHRC supervisors' and managers' 
interpretations did not always align, and so role conflict ensued. Concerns arose over whose direction should be observed and whose priorities should take precedence:

It is quite difficult having an NHS manager at one side and a CLAHRC supervisor and there's been a bit of confusion and crossed lines about having those two roles. [Chris, Diary]

A lot of the time it feels like one is more, I won't say important, but you know one master wants more out of me than the other. [Pat, Interview]

In spite of this, there was consensus that maintaining equanimity was important:

It's just about remaining everybody's friend and being neutral. [Jo, Diary]

In summary, the intermediaries' experiences of their early months in post was coloured by a sense of isolation: isolation from local personnel, potential clients and the active core of the partnership. Furthermore, expressions of uncertainty were commonplace and in part reflected a lack of available means with which to establish an organisational role identity. Uncertainty also centred on particular dimensions of the posts, and the ways in which these differed from other organisational roles. While some of these, such as management, integration, and evaluation have been identified in previous research (Knight \& Lightowler, 2010), the experience of these differences as problematic seems to have been exacerbated by the intermediaries' assessing these in terms of prior understandings of usual organisational roles. This made for an initial setting characterised by role ambiguity. In addition, the management structure of the 
roles and the competing demands of the partners combined to create a sense of role conflict.

\section{Making sense and moving forward}

After the first few months in post, however, there was a discernible attitudinal shift. The isolation, the lack of a singular strategy for action, and the general ambiguity of their position were increasingly presented as positive aspects of the roles. For example, as the participant below notes, the more distanced management facilitated independent and autonomous working:

I manage myself. I mean most of the time there'll be days where I am - I could be in Spain, nobody would even know. [LAUGHS] I work very autonomously. [Sam, Interview]

The absence of a firm strategy was now viewed as advantageous in that it allowed the intermediaries the freedom to tailor their practice to their local context and to their own skills and interests:

Because you didn't have "you must do this, you must do that" it has worked in our favour because you have been able to... well, adapt, because "my [organisation] needs this and your [organisation] needs that". [Jan, Focus group]

The early data, recounted in the previous section, revealed the intermediaries recognised that role conflict was a problem they faced and remaining neutral had been seen as an appropriate and necessary response to this. In practice through time, 
however, the intermediaries started to align themselves with the needs of the organisations in which they sat and latterly tended to speak in terms of 'my organisation'.

[The open strategy] has given us the opportunity to evolve our own roles in ways that we wouldn't have had the opportunity to do, not just for our own benefit but for the benefit of our [organisations]. That has given us a lot of freedom. [Lee, Focus group]

Their descriptions of their experience of the roles also reflected change:

Something in all of us has basically changed... "well it's not going to change if we're sitting there waiting for a sense of direction": we're not getting it and it turned to "what can we do about it?" [Ali, Interview]

Talk of isolation and uncertainty was, through time, replaced by more optimistic references to 'opportunity' and 'autonomy'.

What, then, accounted for this change? The intermediaries cited the importance of communication and social support among themselves as having been key. When the posts were established, no forum existed for cross-intermediary communication. Despite this, as the posts were filled, they increasingly turned to their opposite numbers to discuss their situation and seek solutions to the problems they encountered. Thus a 'community of practice' developed spontaneously (Wenger, 1999).This served three functions. First, it offered a space which enabled the intermediaries to collectively develop a frame of reference for the role, and identify 
the limits and scope of what could be done based on their experiences so far. Collectively, they determined that the ambiguity and conflict surrounding the remit and management was a feature of the roles rather than the product of individual deficits, that it was likely to continue, and that there was little likelihood of any externally driven change. They therefore resolved that developing a proactive and autonomous stance was legitimate if they were to move forward. They also recognised that they were working in quite markedly different contexts and that, although there was some common ground, a large component of their work would have to be tailored to context. This new approach was supported and endorsed collectively, and came to be considered a normative feature of their practice.

Second, the community of practice also acted as a learning resource in which knowledge and strategies could be exchanged and expertise shared:

I'm not saying it's all wonderful now, but it has improved, probably because we've taken the initiative and we have got together [and] like you were saying, you've learnt from Jan and you know I've learnt a lot from the way that Ali works. [Lee, Focus group]

Third, it provided a space in which emotional expression was acceptable, and so the sense of frustration and the experience of stress could be acknowledged and discussed:

I definitely think having six other people to talk to about this definitely helps and yeah I'm often 'what do you think we should do about this?' and 'or on this' or 'this stupid e-mail' and definitely, it definitely helps, so even if it's just 
keeping me calmer and not getting me so frustrated with things. [Chris, Focus group]

The development of the community of practice, and the attendant social support and practical resources it provided, became a valuable asset for making progress in the

roles and seemed to ameliorate the negative experience felt by many. So, for example, the uncertainty and role ambiguity that had pervaded their early experience of the posts could be re-evaluated and affirmed as a characteristic of their roles rather than a personal issue. Furthermore, the problem of role conflict was perhaps moderated by further defining their roles in relation to the needs of the NHS organisations.

\section{Unresolved and irresolvable?}

Whilst the intermediaries had reconciled and adapted themselves to some aspects of the posts, others remained unresolved. A common concern was what the roles offered in terms of career development, as no career pathway was obvious:

There's not like boundary spanner, senior boundary spanner, director of boundary spanning. You're not a specialist in this, you're not a specialist in that, so in terms of a more senior position it's difficult. [Jan, Focus group]

Most expected that they would return to a conventional role in an organisation. When reflecting on how their experience in an intermediary role would impact on their return, many were positive, suggesting that the varied activities they had undertaken would enhance their CVs, equipping them with the transferable skills that arose from these 'boundaryless careers' (Dany et al., 2003). Concerns around evaluation and 
reward, however, remained, reflecting the issues raised above with respect to identifying suitable outcome measures for evaluating intermediary work. Most felt a lack of ownership of their work and considered that much of it went unrecognised. Whilst this was acknowledged as a risk of undertaking intermediary work, they felt that it was a problem which the management of the collaboration should seek to resolve:

It is the kind of nature of boundary spanning that you kind of dip into things a bit and then you set things going and then you don't in a sense have ownership of those things and so it needs to be acknowledged as part of the organisation involved that you won't have a whole list of projects to your name. [Lee, Interview]

This was a continuing source of frustration and impacted negatively on their sense of job satisfaction and value:

I do think it's quite frustrating at times; it's very difficult to know when you've done a good job...Often you can have a couple of bad weeks where you think 'I'm not making any difference here'. [Chris, Interview]

Though the intermediaries had become more positive towards some of the distinctive characteristics of intermediary work, sources of vexation remained. The roles had provided the opportunity to acquire a wide range of transferable skills, but there was little indication that any would continue working in an intermediary position. A key reason for this centred on an inability to translate the scale and scope of their work into something that would be acknowledged and rewarded in conventional terms, and 
a perceived lack of effective action by the collaboration's partners towards addressing this.

\section{Discussion}

The intermediary roles here differ from some described in the literature, as full-time roles in the field of healthcare research translation. As noted above, they also differed from each other in some respects. Nevertheless, the findings strengthen the argument that there are context-independent challenges associated with intermediary work. In drawing on literatures that have previously been neglected in considering knowledgebrokering roles in healthcare (e g, Needleman \& Needleman, 1974, Stamper \& Johlke, 2003,Knight and Lightowler,2010) and in applying some of the insights from these in our empirical analysis of these intermediaries, we highlight how some of these challenges arise from generic features of intermediary work. To this extent, our findings are pessimistic in that they suggest that negative personal consequences result inevitably from the intermediary role.

The experience of isolation and confusion seen in this study is not unexpected, given what is already known of the contingent and context-dependant nature of intermediary work (Jackson Bowers et al, 2008, Ward et al, 2009, Meyer, 2010).The lack of definition and structure that distinguishes such work from usual organisational roles and enables its flexibility and contingency, creates a working environment in which expected points of reference and a clear direction for action are absent. Thus, as above, these conditions can make for a negative work experience in that they can engender, through role conflict and role ambiguity, role stress (Farr and Ford, 1990). 
What this study highlights in particular is that this experience is exacerbated, and therefore made more consequential, in full-time intermediary posts, where the entirety of one's role (and thus social location and professional identity) is defined by intermediary status In these cases, the absence of available norms and understandings of such roles can serve to inhibit the building of both the situational definitions of the roles within the organisations, and the self-definitions of the actors in the roles ( Ashforth \& Mael, 1980).

However, our analysis also suggests that these challenges can be mitigated, and even made into a resource for the 'successful' realisation of intermediary work. Here we add healthcare-specific substance to the suggestions of, for example, Schaubroeck et al. (1993), and Tang and Chang, (2010), who highlight the importance of social support and other factors in mediating role conflict and moderating role ambiguity to achieve a more positive impetus towards flexibility and creativity. Role tensions could, through time, be reconciled, though this did seem to mean aligning more with one partner than the other. To this extent, the liminality of the roles proved an advantage, since it meant that—once initial uncertainties and doubts were overcomethe role-holders could be creative and autonomous in their work. They could find novel opportunities and turn their positional ambiguity into an advantage - a crucial task if this kind of intermediary work is to make inroads into the task of knowledge translation (CHRSF, 2003). This speaks to the possibility of crafting intermediary roles from the 'bottom up' in response to new challenges that span boundaries, though this ability was contingent on several factors: (a) the existence of a plurality of organisational aims with which to align (an acknowledged feature of public-service 
bureaucracies such as universities and healthcare organisations which may not apply in all fields); (b) a degree of acceptance that, at least in the short-term, these roles could not readily be delimited or assessed against clear criteria of value-i.e. that they necessitated taking risks and undertaking a range of pursuits, not all of which would pay off; and (c) collective forums (the intermediaries' community of practice) in which to share concerns, ideas and opportunities, pool creativity, and form a collective identity by which to positively define the group and defend its interests from organisations that were less willing to embrace this uncertainty. In this study, the existence of others in similar roles enabled the intermediaries to begin to make sense of the roles and unite the disparate possibilities offered into a coherent, yet flexible, plan of action. This move to action was delineated, endorsed and supported within the community of practice that had formed serendipitously. This community of practice also provided the means by which a frame of reference was developed and served to mitigate the sense of role ambiguity by enabling a role identity to evolve and become established.

What was also revealed was that the generation of a role identity came at a cost in terms of maintaining neutrality. The site of intermediary work may be legitimately described as a distinctive space, but this space may, more often than not, be contested, unstable, and shaped by institutional and psycho-social pressures. The need of the actors to moderate role ambiguity demanded greater role definition. This definition was, in part, achieved by a greater alignment with the needs and agendas of the organisations in which the roles were enacted, reflecting the findings of studies carried out in other contexts such as academia (Knight and Lightowler, 2010) and community 
planning departments (Needleman and Needleman, 1974). This has implications for such roles themselves in that, in practice, certain conditions of intermediary work which are sources of role conflict (e.g. managing competing agendas, and operating between differing world views and cultures) create an environment which exerts a destabilising 'push/pull' pressure on the intermediary as they strive for a neutral position. This raises questions about the extent to which exposure to such conditions can, or should, be expected and tolerated. Further, how effective might long-term intermediary roles in practice be, given the challenge of serving two masters and the potential this creates for such roles to be assimilated into one or another agenda?

The institutional context in which the roles were enacted further encouraged alignment in that there was no clear career path for an intermediary, 'boundaryless' or 'portfolio' career (Currie et al., 2010). Intermediary work is not institutionalised in terms of certification and regulation. The result is that the intermediaries were understandably attracted back to the greater security and prospects of a normal, recognisable organisational role, embedded within conventional hierarchies, structures and reward systems. Although many felt that intermediary work had provided the opportunity to gain transferable skills, it was not felt to fit well within a career pathway, or to be readily understood or valued as an occupation by other employers. Once again, then, the viability of intermediary work as an on-going career choice, and thus the sustainability of full-time intermediary roles in particular, seems questionable (Currie et al., 2010). 
So what might be done to better realise the potential of such roles? Clearly, there is a need for greater awareness and recognition of the potential problems intermediaries face in order to attract and retain the creative, innovative, and selfmotivated personnel that are necessary for such roles to be effective. As above, embedding this awareness into tailored forms of social support and making this available to intermediaries is critical (cf. Knight and Lightowler 2010, Tang and Chang 2010). Further, organisations should ensure that intermediaries are made more aware of, and better prepared for, these potential problems before they undertake their roles, thus facilitating an easier and more efficient transition into such work. The novelty of such roles can mean that a good deal of the intermediary's initial time in post is taken up in explaining the purpose and function of the role to others. This could be reduced by concentrated efforts by management to identify and better publicise the roles to their potential client base early on in the intervention. In addition, given that many forms of intermediary work are dependent on social contact, practical consideration should be given to the best physical location for such roles. We have shown that being isolated physically as well as socially is problematic and can impact negatively both on the individual and the potential efficacy of the intervention. The issue of physical location and attendant questions of where best to locate intermediaries in relation to the groups they work with have been little considered; our findings suggest that these are potentially consequential and merit further exploration.

How best to structure the management of such roles remains unclear. The joint management described here brought an additional dimension of role conflict over and above that which might have been expected from satisfying the competing demands of 
the groups they were working between, as it sometimes produced conflicting directives which also had to be managed. Being managed by one or other partners in the collaboration would perhaps have moderated this but it might have been at the expense of creating an increased pressure to orient to the interest of that partner.

The problem of adequately capturing the effectiveness of intermediary work remains. Again, there is no easy means by which this can be addressed, although a greater awareness that the problem exists for intermediaries would be helpful to the individual and to their prospects of finding an appropriate role. We acknowledge that the roles considered here were novel in the organisations they were enacted in and possibly, over time, the organisations would develop pathways for intermediary careers to progress. This possibility, however, is contingent on viable and appropriate evolutional processes being developed in order that the roles can be seen to have demonstrable value. It may also be that instituting some form of formalised certification would go some way to alleviating the 'career risk' that such roles were felt to carry by bringing them into the institutional occupational mainstream. Should this be the case, a balance needs to be struck between role definition and specification and the lack of constraint such roles need in order to retain their flexibility and responsiveness. However, the appeal of a 'less-bounded' career, as Currie et al. (2010) term it, such as intermediary work, is unlikely to be sufficient to attract any but the least risk-averse individuals, as long as professional institutions and organisational structures fail to make room for such skill sets with clear career paths and opportunities. While doing 'intermediary work' as part of a wider, more conventional role might offer an attractive and distinctive transferable skill set, a full-time 
'intermediary role' risks casting the role-holder adrift between institutions and occupational fields.

\section{Conclusion}

In highlighting issues raised in previously untapped literatures about similar roles, and in our empirical analysis of intermediary roles in a partnership for healthcare research translation, we suggest a number of cautionary lessons for the viability and sustainability of such roles in overcoming knowledge gaps. The current popularity of intermediary roles in translational contexts is, perhaps, ironic given the uncertainties in the evidence base for such interventions. In particular, our study suggests that the consequences for individuals occupying such roles have implications for the very feasibility of intermediary roles, particularly as full-time posts where individuals lack access to social support structures and normative expectations that can moderate role tensions. We also highlight ways in which such challenges can be mitigated, though note that, to some extent, this means 'diluting' the characteristics that make the roles distinctive in the first place, such as their equanimity. Furthermore, we suggest that structural issues around professional boundaries, organisational norms and career pathways may make such roles difficult to sustain in the long-term, and these seem much less amenable to intervention. In all, our study suggests that, despite the intuitive appeal of intermediary roles as a knowledge-translation solution, organisations should think carefully about how best to realise them if they are to achieve their potential in a sustainable manner. 


\section{References}

Ashforth,B.\&Mael,F. (1980) 'Social identity theory and the organisation' The Academy of Management Review 14 no (1):20-39

Barnett,R. (2003) 'Foreword', in N Jackson (Ed.) Engaging and changing higher education through brokerage, Aldershot: Ashgate.

Britten,N. (2010) 'Qualitative Research and the Take-up of Evidence into Practice', Journal of Research in Nursing, 15(6):537-544.

Charmaz,K. (2006) 'Constructing Grounded Theory', London: Sage, .

CHSRF (2003) 'The Theory and Practice of Knowledge Brokering in Canada's Health System', http://www.chsrf.ca/migrated/pdf/Theory_and_Practice_e.pdf

Cooksey,D. (2006) 'A review of UK health research funding', Norwich, HMSO

Currie,G. Finn,R. \& Martin,G.P. (2010) 'Role transition and the interaction of relational and social identity: new nursing roles in the English NHS', Organization Studies 31(7): 941-961

Dany,F., Mallon,M \& Arthur,M.B.(2003) 'The odyssey of career and the opportunity for international comparison', International Journal of Human Resource Management 14(5):705-721

Davies,H. Powell,A. Ward,V. Smith,S. (2011) 'Supporting NHS Scotland in developing a new Knowledge- to-action model', http://www.knowledge.scot.nhs.uk/media/CLT/ResourceUploads/4002569/K2A_Evidence.p df

Dobbins,M. Hanna,S. Ciliska,D. et al. (2009) 'A randomized controlled trial evaluating the impact of knowledge translation and exchange strategies', Implementation Science, 4(1): 61-61.

Estabrooks,C.A., Derksen,L., Winther,C. et al. (2008) 'The intellectual structure and substance of the knowledge utilization field: A longitudinal author co-citation analysis 1945 to 2004', Implementation Science, 3(49)

Farr,J. and Ford,C. (1990) 'Individual Innovations', in J. Farr (ed.) Innovation and Creativity at Work, Wiley: New York

Fixsen,D., Naoom,S. Blase,K., Frieman,R., \& Wallace,F. (2005) 'Implementation Research: A Synthesis of the Literature', http://nirn.fmhi.usf.edu/resources/publications/monograph. 
Gerrish,K., Nolan,M., Kirshbaum,M., McDonnell,A. Tod,A. \& Guillaume,L. (2011) 'The role of advanced practice nurses in knowledge brokering as a means of promoting evidence-based practice among clinical nurses', Journal of Advanced Nursing, 67(9): 2004-2014

Glaser, B. (1965). The Constant Comparative Method of Qualitative Analysis. Social Problems, 12(4), 436

Haines,A. Kuruvilla,S. \& Borchet,M. (2004) 'Bridging the implementation gap between knowledge and action for health', Bulletin of the World Health Organization, 82(10): 724-732

Haynes,R.B. \& Haynes,G.A. (2009) 'What does it take to put an ugly fact through the heart of a beautiful hypothesis', Evidence- based Medicine, 14(3): 68-69.

Jackson-Bowers E, Kalucy L, McIntyre E.(2006) Focus on... Knowledge Brokering. Primary Health Care Research and Information Service; Adelaide

Kerner,J.F. (2006) 'Knowledge translation versus knowledge integration: a "funder's" perspective, Journal of Continuing Education in the Health Professions', 26(1):72-80

Knight \& Lightowler, C. (2010) 'Reflections of "Knowledge exchange professionals" in the social sciences: emerging opportunities and challenges for university based knowledge brokers', Evidence and Policy, 6(4): 554-556.

Lomas,J. (2007) 'The in-between world of knowledge brokering', British Medical Journal, 334(129)

Lyons, R.F. (2010) 'Using Evidence: Advances and Debates in Bridging Health Service Research and Action', Halifax, Nova Scotia: Atlantic Health Promotion Research Centre

Martin,G.P., McNicol,S. \& Chew,S. (in press) 'Towards a new paradigm in applied health research and practice? Collaborations for Leadership in Applied Health Research and Care', Journal of Health Organization \& Management

Meyer,M. (2010) 'The Rise of the Knowledge Broker', Science Communication, 32(1):118-127

Needleman,M.L. \& Needleman,C.E. (1974) 'Guerrillas in the Bureaucracy: Community Planning Experiment in the United States', New York: Wiley

Newland, C. A.(1981). 'Local government capacity building'. Urban Affairs Papers $3(1): 4-5$. 
Oborn,E, Barrett,M. \& Racko,G. (2010) 'Knowledge Transaction in Healthcare', http://www.jbs.cam.ac.uk/research/working_papers/2010/wp1005.pdf

Oldham,A. \& McLean,R. (1997) 'Approaches to Knowledge Brokering', http://www.iisd.org/pdf/2001/networks_knowledge_brokering.pdf

Russell,D.J. Rivard,L.M., Walter,S.D. et al. (2010) 'Using knowledge brokers to facilitate the uptake of pediatric measurement tools into clinical practice: A beforeafter intervention study', Implementation Science, 5 (1)

Schaubroek J, Ganster DC, Sime WE, Ditman D (1993). A field experiment testing supervisory role clarification. Personnel Psychol.,46:1-25.

Simmel,G. (1950) 'The Triad', in . K.H. Wolff (ed) The Sociology of George Simmel, New York: Free press: 145-69.

Stamper,C. \& Johlke,M. (2003) 'The Impact of Perceived Organizational Support on the Relationship between Boundary Spanner Role Stress and Work Outcomes', Journal of Management, 29(4):569-588.

Stovel,K. \& Shaw,L. (2012) 'Brokerage', Annual Review of Sociology, 38(1):139-159

Tang,Y \& Chang,C. (2010) 'Impact of role ambiguity and role conflict on employee creativity', African Journal of Business Management, 4(6): 869-881

Tooke,J. (2007) 'Report of the high level group on clinical effectiveness'. London: Department of Health

Tushman,M. (1977) 'Special boundary roles in the innovation process', Administrative Science Quarterly, 22 (4): 587-605.

Ward,V., House,A. \& Hamer,S. (2009) 'Knowledge brokering: The missing link in the evidence to action chain?', Evidence and Policy, 5 (3):267-279.

Wenger,E. (1999) 'Communities of practice’. Cambridge: Cambridge University Press.

Williams,P. (2002) 'The Competent Boundary Spanner', Public Administration, 80(1): 103-124.

Zaim,S., Landry,R. \& Amara,N. (2009) 'Knowledge Brokers: a winning strategy for improving knowledge transfer and use in the field of health'. International Review of Business Research Papers 5 (4): 491-505.

Zimmerman,D. \& Weidener,D.(1977) 'The Diary-Interview Method', Urban Life, 5(4):479 